EPJ Web of Conferences 45, 01009 (2013)

DOI: $10.1051 /$ epjconf/20134501009

(C) Owned by the authors, published by EDP Sciences, 2013

\title{
CFD simulation and experimental analysis of erosion in a slurry tank test rig
}

\author{
Mehdi Azimian and Hans-Jörg Bart ${ }^{\mathrm{a}}$
}

\begin{abstract}
Erosion occurring in equipment dealing with liquid-solid mixtures such as pipeline parts, slurry pumps, liquid-solid stirred reactors and slurry mixers in various industrial applications results in operational failure and economic costs. A slurry erosion tank test rig is designed and was built to investigate the erosion rates of materials and the influencing parameters such as flow velocity and turbulence, flow angle, solid particle concentration, particles size distribution, hardness and target material properties on the material loss and erosion profiles. In the present study, a computational fluid dynamics (CFD) tool is used to simulate the erosion rate of sample plates in the liquid-solid slurry mixture in a cylindrical tank. The predictions were made in a steady state and also transient manner, applying the flow at the room temperature and using water and sand as liquid and solid phases, respectively. The multiple reference frame method (MRF) is applied to simulate the flow behavior and liquid-solid interactions in the slurry tank test rig. The MRF method is used since it is less demanding than sliding mesh method (SM) and gives satisfactory results. The computational domain is divided into three regions: a rotational or MRF zone containing the mixer, a rotational zone (MRF) containing the erosion plates and a static zone (outer liquid zone). It is observed that changing the MRF zone diameter and height causes a very low impact on the results. The simulated results were obtained for two kinds of hard metals namely stainless steel and ST-50 under some various operating conditions and are found in good agreement with the experimental results.
\end{abstract}

\section{Introduction}

Hydro-erosion occurs in practice in two ways, one is the erosion by a cavitating liquid and the other is the erosion by solid particles entrained in liquid flow known as slurry erosion.

In the flows of liquid-solid mixtures (two-phase flows), the material removal from the equipment components is mainly caused by the solid particles and the material loss caused by corrosion is relatively minor. Some of application examples are in processing technology such as stirrers in flotation cells for the wet metal processing or pumps for water treatment, mining and smelting industry, pipes in materials handling with hydraulic contaminant of grained solids (sand, coal, ore, fly ash), turbines and control devices in hydropower engineering especially with high water amount or exposed to flooding [1].

The machinery and equipment dealing with the liquid-solid flows could be damaged by erosion leading to low operational efficiency and short service life with frequent overhaul. In order to reduce the erosion of the machinery the following approaches could be considered; a) Manufacturing technology b) Selection of type and parameters of machines. c) Operational control. d). Erosion resistant design. e) Erosion resistant material.

${ }^{\mathrm{a}}$ E-Mail: bart@mv.uni-kl.de f) Predicting the erosion rates and locations.

Erosion occurs due to plastic deformation and cutting. Deformation wear takes place when the particles hit the target material perpendicular. Cutting wear on the other hand, is associated with particle velocity parallel to the wear. Finnie and Trustcott $[6,7]$ have reported that erosion in slurry pipelines is mainly caused by the cutting impact of suspended solid particles, since the angle of particles impact in pipe flow is relatively small.

The material removal is determined by the laws of fluid mechanics and properties of the liquid-solid mixture and the target material properties. The flow properties are dependent of the component geometry, surface topography and flow rate. On the other hand the physical properties of the two-phase mixture are affected by the solid particles concentration, size distribution, type, shape, density, hardness and sand settling velocity.

The wear tests in pilot plant test loops are time consuming and quite expensive, therefore it is very useful to develop a method to predict the local erosion rate in slurry handling equipment based on the measurements in a slurry tank test rig.

The erosion wear of a material in contact with a flowing suspension can be determined by the target

This is an Open Access article distributed under the terms of the Creative Commons Attribution License 2.0, which permits unrestricted use, distribution, and reproduction in any medium, provided the original work is properly cited. 
material loss per unit area or loss in thickness namely as penetration rate under the dynamic and continuous action of solid particles. The unit of erosion wear is usually given per unit time or per unit solid particle throughput [2].

Investigations on the suspension of solid particles in a cylindrical tank test rig by Sharma et al. [3] suggested that a propeller directing the liquid-solid mixture downwards towards the bottom of the cylinder provides better uniform distribution of solid particles in comparison to upwards directing impellers. Biswas et al. [4] observed that application of a pitched turbine blade propeller provides better suspension of solids at lower speeds compared to that of the butterfly type propeller.

Desale et al. [5] found that the propeller rotational speed required for uniform distribution of solid particles in the tank varies with particle size, specific gravity and concentration of solid particles and have called this speed as the suspension speed.

The present work reports experimental investigations and CFD simulation of erosion wear of two hard metals in water-sand slurry mixture in a cylindrical tank tester and studying the dependence of erosion wear to influencing parameters.

\section{Experimental setup}

The test rig as schematically depicted in Fig. 1 contains a cylindrical glass tank having a diameter of $294 \mathrm{~mm}$ and height of $500 \mathrm{~mm}$. The slurry is kept in suspension by a propeller. A motor below the tank is connected to a shaft which holds the impeller. Bearings are used to support the rotating shaft and a hardened seal as depicted in Fig. 2 is provided to prevent the leakage of water from the bottom. Another motor is located at the top of the test rig connected to a shaft to rotate the erosion plates fixed to a holding arm. The rotating direction of upper motor should be in opposite direction compared to the bottom motor. It provides effective distribution of solid phase in liquid phase and minimizes the relative velocity effect. The erosion plates could be weighted before and after each test to determine the mass loss of each plate.

\section{Multiphase modeling approach}

A multiphase flow containing dispersed particles may be modeled using either the particle transport model or the Eulerian-Eulerian multiphase model.
In Eulerian-Eulerian multiphase, a momentum equation needs to be solved for each representative size which becomes very costly.

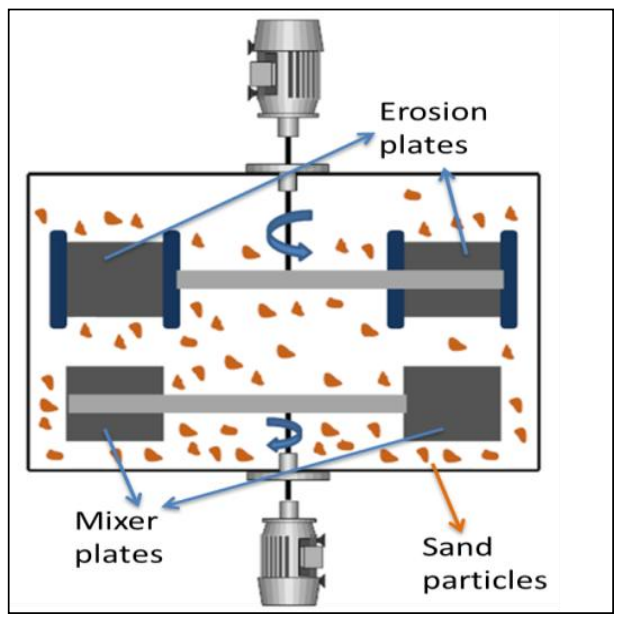

Fig. 1. Schematic view of the slurry tank test rig

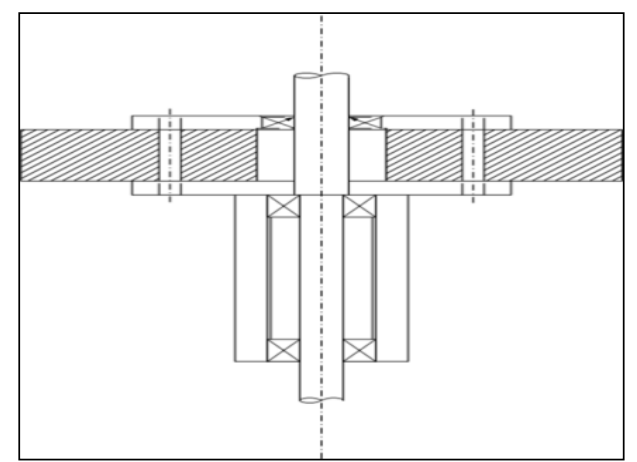

Fig. 2. Schematic view of the hardened flange and bearing at bottom of the tank

The particle transport model is applied in the present study since it is more flexible when there is a significant size distribution leading to different particle velocities and provides more detail information on behavior and residence time of individual particles. However, the turbulence model used in a particle tracking simulation only applies to the continuous phases. Turbulence can affect the particles through the particle dispersion force, but the particles can have no effect on the turbulence of the continuous phase, other than indirectly by affecting the velocity field [6].

The typical sand particle diameter distribution is in the range of 0.1 to $0.5 \mathrm{~mm}$ in pipelines as it is depicted in Fig. 3 from experimental measurement by a HORIBA particle size analyzer (manufactured by Retsch GmbH, Hann) at our laboratory. 
Pepple [7] applied the phase doppler method for dilute, turbulent liquid-solid flow in a vertical pipe and demonstrated that in general, the particles in the range of $0.5 \mathrm{~mm}$ damp the fluid turbulence while the particles in the range of $1.0 \mathrm{~mm}$ and $1.5 \mathrm{~mm}$ are either neutral or enhance the turbulence.

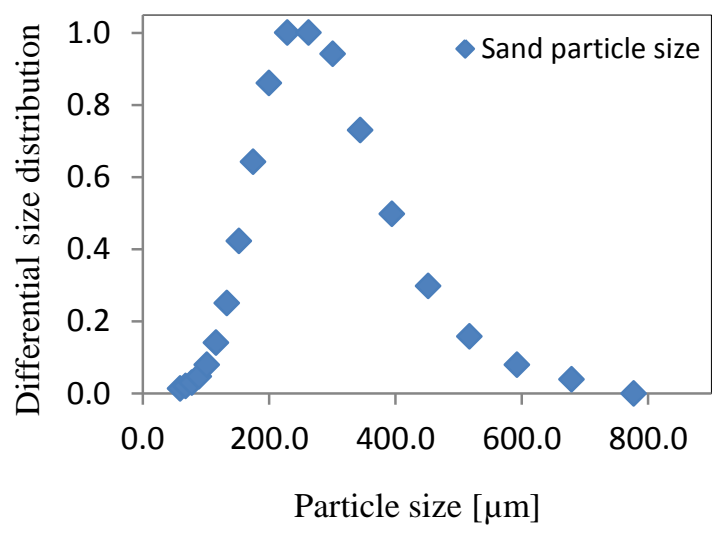

Fig. 3. Measured differential size distribution of sand particles

\subsection{Governing equations of particle phase using the Lagrangian approach}

Lagrangian-Eulerian model for liquid-solid particle flow contains an Eulerian formulation for the liquid phase and the Lagrangian formulation for the particle phase together with a stochastic dispersion model to calculate the influence of liquid phase turbulence on the solid particle phase. Many researchers have conducted in common that detailed inlet conditions play an important role in accurate Lagrangian predictions, and that a large number of particle trajectories are required to gain a stochastically significant solution [8].

\subsection{Lagrangian equation for solid particles}

In the Eulerian-Lagrangian model, the liquid phase is simulated by applying the Eulerian conservative equations of continuity and momentums. In the Lagrangian approach, the equation of motion for each of the particle parcel can be written as:

$$
\frac{d \tilde{U}_{p l}}{d t}=\frac{\tilde{U}_{l}-\tilde{U}_{p l}}{\tau_{p}}+F_{p l}
$$

where $\tilde{U}_{l}=U_{l}+u_{l}$ is the instantaneous liquid velocity, $F_{p l}$ is an external force. The response time of particle, $\tau_{p}$, is defined as:

$$
\tau_{p}=\frac{\rho_{p} D_{p}^{2}}{18 \mu f_{p}}
$$

where $f_{p}=1+0.15 \operatorname{Re}_{p}^{0.687}$ and $\quad\left(0<\operatorname{Re}_{p}\right.$ <1000), $\rho_{p}$ and $D_{p}$ are the particle density and particle diameter, respectively.

The particle trajectories are computed by:

$$
\frac{d x_{p l}}{d t}=\tilde{U}_{p l}
$$

The two way coupling source between the liquid and solid particle phases is given by:

$$
S_{U k}^{p}=-\sum \frac{\pi}{6} \rho_{p} D_{p}^{3} \dot{N} \Delta t\left(\frac{\tilde{U}_{l}-\tilde{U}_{p l}}{\tau_{p}}\right)
$$

where, the summation is carried out over all particle trajectories crossing the control volume.

\section{Application of Grant-Tabakoff erosion model}

The selection of an appropriate erosion model which better represents the experimental results was performed by calculating the erosion (material weight loss) of a square shape specimen caused by a hitting vertical water/sand jet for some various operating parameters with four erosion models from literatures [9-13]. The results are then compared with the experimental erosion results of Wang et al. [14] which applied a water/sand jet experimental set-up to investigate the effect of influencing parameters on the erosion rate of hard metals. As it is depicted in Fig. 4, the simulated results of erosion with Grant-Tabakoff model fits very well with the experimental results and thereby was selected for further calculations of the erosion rate of rotating plates in the current study.

Numerical prediction of metallic surface erosion is usually based on the empirical correlation of the given particle-surface material properties associated with the particle impact conditions.

Tabakoff et al. [11, 15] has experimentally indicated that the erosion of a specimen is mostly dependent on the particle impingement angles and its impact velocity.

The uniqueness of this model compared to other erosion models of its kind is that it contains the particle restitution coefficient as an influencing parameter, and in particular the tangential restitution coefficient $R_{T}$ as one of the parameters 


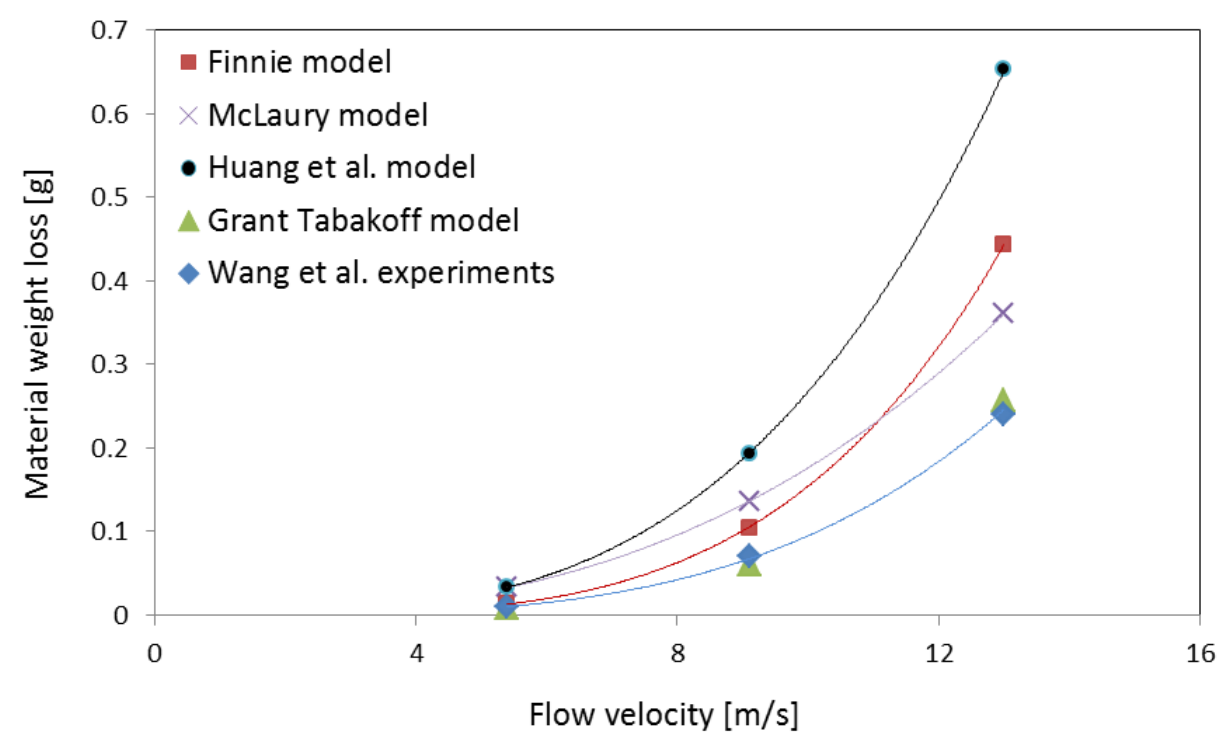

Fig. 4. Erosion predictions with various erosion models and comparison with experimental results

affecting the erosion rate.

The following equation was developed by Grant and Tabakoff [11] to predict the erosion of the ductile materials and alloys and is defined as the ratio of the eroded mass of target material to the mass of impinging solid particles.

$$
E=k_{1} f\left(\beta_{1}\right)\left(V_{1 T}^{2}-V_{2 T}^{2}\right)+f\left(V_{1 N}\right)
$$

where $k_{1}$ is the material constant, $f\left(\beta_{1}\right)$ is the empirical function of particle impact angle, $V_{1 T}$ und $V_{2 T}$ are respectively the tangential component of incoming particle velocity and of rebounding particle velocity and $f\left(V_{1 N}\right)$ is the component of erosion due to the normal component of velocity.

The tangential restitution ratio is defined as follows:

$$
R_{T}=\frac{V_{2 T}}{V_{1 T}}=1-k_{4} V_{1} \sin \beta_{1}
$$

by inserting $V_{1 T}=V_{1} \cos \beta_{1}$, the erosion equation can be rewritten as:

$$
E=k_{1} f\left(\beta_{1}\right) V_{1}^{2} \cos ^{2} \beta_{1}\left(1-R_{T}^{2}\right)+f\left(V_{1 N}\right)
$$

The effect of the particle approach angle is inserted into $f\left(\beta_{1}\right)$, and a strictly empirical approach is used to predict its behavior. The result of this analysis yields the following expression:

$$
f\left(\beta_{1}\right)=\left[1+k_{2} k_{12} \sin \left(\frac{\pi \beta_{1}}{2 \beta_{0}}\right)\right]^{2}
$$

where $\beta_{0}$ is the angle of attack where the maximum erosion occurs, $k_{12}$ is a material constant and

$$
k_{2}: \begin{cases}1 & \beta_{1} \leq 2 \beta_{0} \\ 0 & \beta_{1}>2 \beta_{0}\end{cases}
$$

The component of erosion resulting from normally impacting particles is expressed as:

$$
f\left(V_{1 N}\right)=k_{3}\left(V_{1} \sin \beta_{1}\right)^{4}
$$

Overall erosion rate of the wall due to the solid particles interaction with the wall is finally computed from the following equation:

$$
\dot{E}=\dot{N} \cdot m_{p} \cdot E
$$

where $\dot{N}$ is the number rate of solid particle and $m_{p}$ is the particle mean mass.

\section{Simulation conditions}

The physical properties of water and sand are listed in Table 1.

However, the atomic packing factor for precise determination of the bulk sand density must be taken into account. The atomic packing factor (APF) or packing fraction is the fraction of volume in a bulk structure that is occupied by atoms. For 
one-component materials, the APF is represented mathematically by:

$$
A P F=\frac{N_{\text {atoms }} \cdot V_{\text {atom }}}{V_{\text {unitcell }}}
$$

By assuming the $\mathrm{APF} \approx 0.7$ from literature for the sand bulk, the density of wet sand will be assumed as $2300 \mathrm{~kg} / \mathrm{m}^{3}$ for the CFD simulations.

The CFD simulations are performed to predict how the erosion rate of rotating elements for a specified target material is changing with various influencing parameters. The two important influencing parameters are flow velocity and solid particle concentration which were studied in the current work. The CFD results have been compared and validated with experimental results of erosion mass loss of stainless steel and ST-50 at four various rotational velocities and three various sand weight concentration values in the slurry tank. The experimental tests conditions are presented in Table 2 in more details.

\subsection{Computational domain and MRF method}

Geometry of the slurry tank together with the rotating arm, fixtures and mixer and sample plates as depicted in Fig. 5 were generated and finely meshed in ANSYS-ICEM software. The final mesh consists of three sub meshes. One for the rotating erosion plates, one containing the mixer and the third one for the slurry tank. The advantage is that when for instance, the orientation angle of the erosion plates is varied to investigate the angle effects on the erosion rate, the related mesh part for the erosion plates could be substituted in the final mesh, saving in time and computational efforts.

Since the final mesh contains three sub meshes, it is possible to define three computational zones in ANSYS-CFX, namely by applying the multiple reference frames (MRF) method as it is shown in Fig. 6. Here one rotating reference zone is defined for the erosion plates, one rotating reference zone for mixer and one stationary reference zone for the slurry tank.

Definition of interfaces is necessary between rotating zones and stationary zone. Since the surface mesh of rotating side and stationary side of each interface are not identical, the general grid interface (GGI) method is applied for transforming the information among the interfaces. We have also proved that changing the diameter and height of each of the two rotating zones containing the rotating parts have a negligible effect on simulation results.

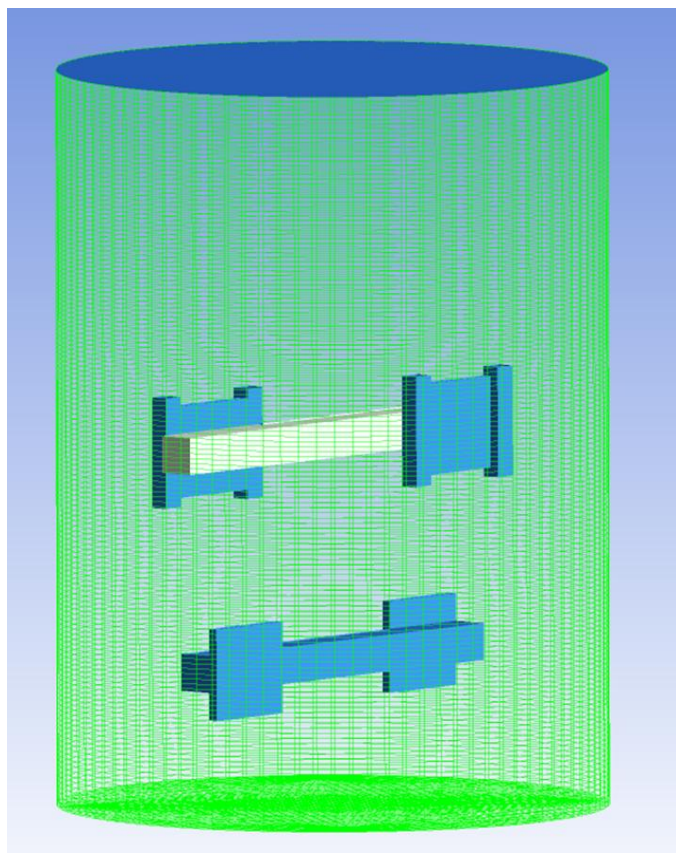

Fig. 5. Geometry modeling of the test rig

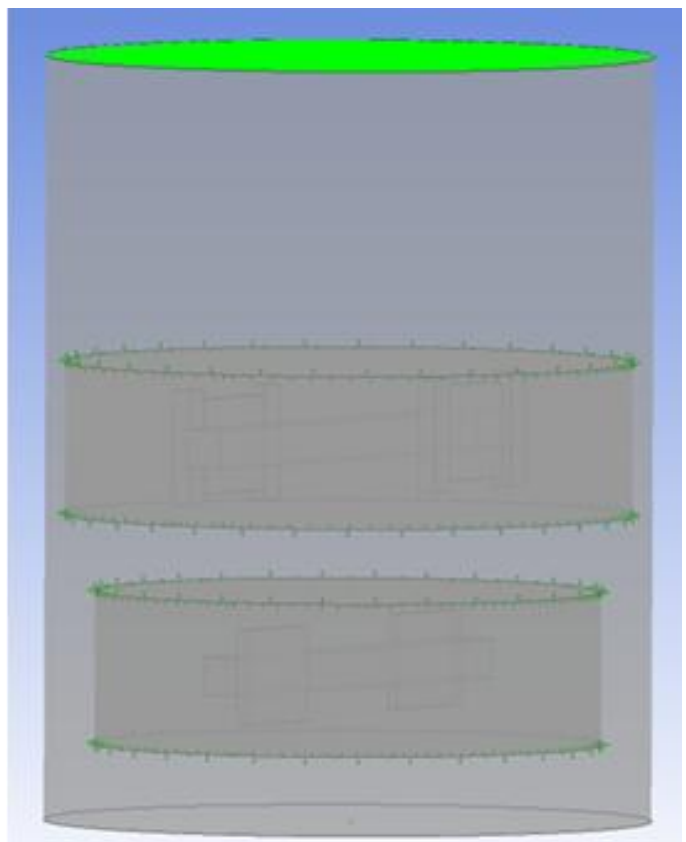

Fig. 6. Multiple reference frames of the computational domain 
Table 1. Physical properties of sand and water

\begin{tabular}{|c|c|c|c|}
\hline \multirow{2}{*}{ material } & $\mathrm{M}$ & $\rho$ & $\mathrm{c}$ \\
\cline { 2 - 4 } & {$[\mathrm{g} / \mathrm{mol}]$} & {$\left[\mathrm{kg} / \mathrm{m}^{3}\right]$} & {$[\mathrm{J} / \mathrm{kgK}]$} \\
\hline Water & 18.02 & 997.0 & 4181.7 \\
\hline Sand (dry) & 60.10 & 1620.0 & 800.0 \\
\hline
\end{tabular}

Table 2. Experimental test runs to investigate the flow velocity and sand concentration effects

\begin{tabular}{|c|c|c|c|c|}
\hline Test & $\begin{array}{c}\text { Sand } \\
\text { concentration } \\
{[\text { weight \%] }}\end{array}$ & $\begin{array}{c}\text { Plate } \\
\text { material }\end{array}$ & $\begin{array}{c}\text { Mixer } \\
\omega \\
{[\text { RPM] }}\end{array}$ & $\begin{array}{c}\text { Erosion } \\
\text { plates } \omega \\
{[\text { RPM] }}\end{array}$ \\
\hline 1 & 10 & $\begin{array}{c}\text { Stainless } \\
\text { steel }\end{array}$ & 200 & -200 \\
\hline 2 & 10 & $\begin{array}{c}\text { Stainless } \\
\text { steel }\end{array}$ & 160 & -160 \\
\hline 3 & 10 & $\begin{array}{c}\text { Stainless } \\
\text { steel }\end{array}$ & 120 & -120 \\
\hline 4 & 10 & $\begin{array}{c}\text { Stainless } \\
\text { steel }\end{array}$ & 80 & -80 \\
\hline 5 & 10 & ST-50 & 200 & -200 \\
\hline 6 & 10 & ST-50 & 160 & -160 \\
\hline 7 & 10 & ST-50 & 120 & -120 \\
\hline 8 & 10 & ST-50 & 80 & -80 \\
\hline 9 & 5 & $\begin{array}{c}\text { Stainless } \\
\text { steel }\end{array}$ & 120 & -120 \\
\hline 10 & 8 & $\begin{array}{c}\text { Stainless } \\
\text { steel }\end{array}$ & 120 & -120 \\
\hline 11 & 10 & $\begin{array}{c}\text { Stainless } \\
\text { steel }\end{array}$ & 120 & -120 \\
\hline 12 & 5 & ST-50 & 120 & -120 \\
\hline 13 & 8 & ST-50 & 120 & -120 \\
\hline 14 & 10 & ST-50 & 120 & -120 \\
\hline
\end{tabular}

\section{Results}

Erosion mass loss of stainless steel and steel 50 (ST-50) in water-sand slurry mixture has been measured at different rotational velocities and different sand concentrations. The mass loss of stainless steel and ST-50 have been evaluated in the tank test rig with $10 \%$ weight concentration and at four various rotational velocities of erosion plates and mixer plates from 80 RPM to 200 RPM and is depicted in Fig. 7. It has been observed that the erosion increases with increase in rotational velocity and the erosion mass loss of ST-50 is reasonably higher than stainless steel; this is expected since the hardness of ST-50 is smaller than the stainless steel hardness. It is seen that only at rotational velocity of 80 RPM the mass loss of both materials were reported almost to have the same value, since it has been observed that 80 RPM is lower than the suspension speed which is the minimum propeller rotational speed required for uniform distribution of solid particles in the tank.

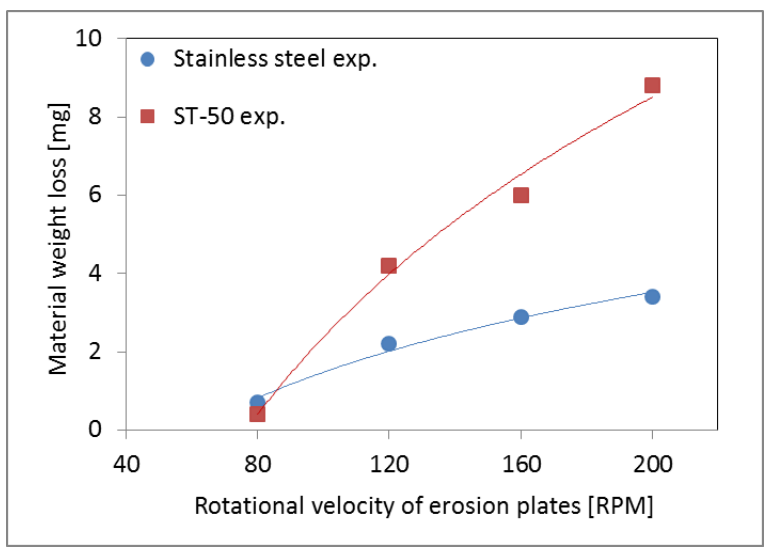

Fig. 7. Comparison of material loss of stainless steel and ST-50 in various rotational velocities

The material weight losses of stainless steel and ST-50 in the slurry tank were reported at constant rotational velocity of 120 RPM for sand particles sized from 0.1 to $0.5 \mathrm{~mm}$ and with $5,8,10$ sand weight concentrations and is presented graphically in Fig. 8. As depicted the erosion mass loss increases logarithmic with increase in sand concentration and the mass loss of ST-50 is more than two times higher than the mass loss of stainless steel.

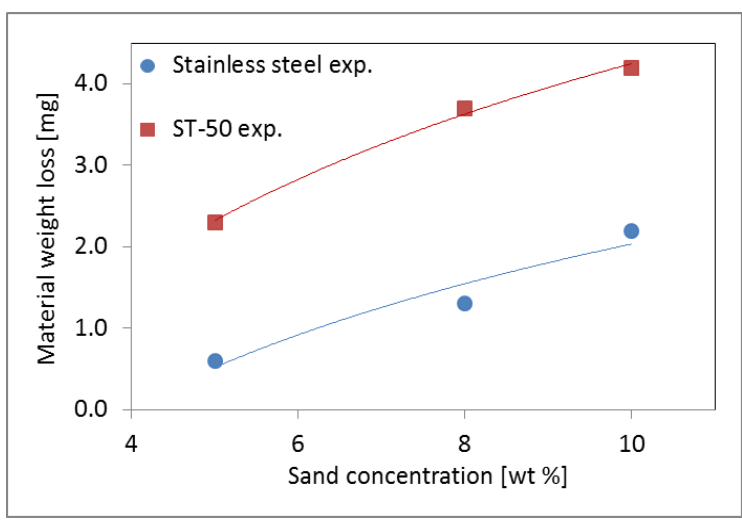

Fig. 8. Comparison of material loss of stainless steel and ST-50 in various sand concentrations

CFD results of mass loss of stainless steel are compared with experimental values for different rotational velocities and sand concentrations and are shown in Fig. 9 and Fig. 10, respectively.

The CFD results are qualitatively in good agreement with experimental results for both cases, however some variations are observed. One reason could be the assumption of sand particles as solid transport particles which provides to set an injection source for the solid particles. Currently the coupling of erosion models with CFD tools such as FLUENT and ANSYS-CFX are only possible when 
the solid particles are defined as solid transport particles. Thereby, in present study the whole amount of sand was assumed to inject to the domain from a central point source in the tank. Another important reason is due to complexity and variably of the flow patterns inside the tank compared to the conditions which the erosion models have been experimentally generated. This means an erosion model which was generated for instance in accordance with the experiments with a water jet test rig, might not precisely predict the erosion rate quantities in a slurry tank test rig. It was also approved that the opposite rotational directions of impeller and erosion plates plays an important role causing more difficulties in convergence of simulations as compared to the case having identical rotational directions.

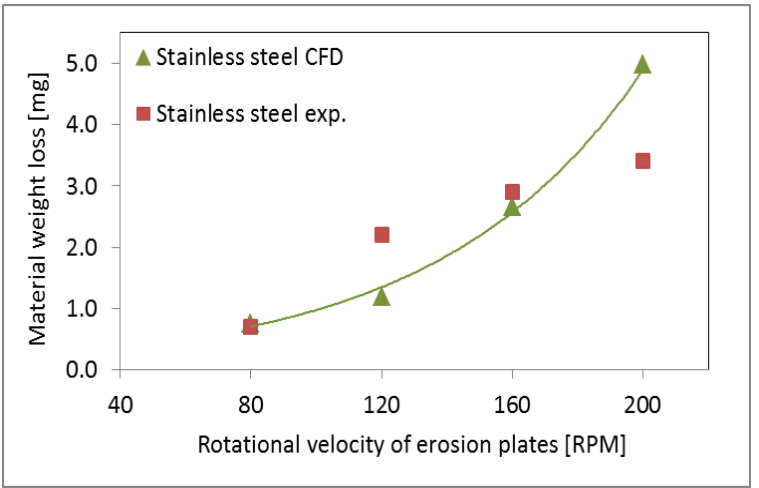

Fig. 9. Validation of CFD and experimental erosion results of stainless steel in various rotational velocities

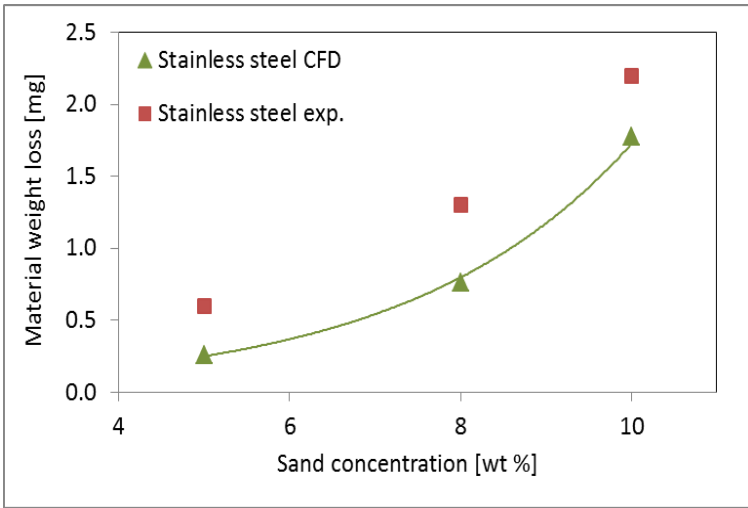

Fig. 10. Validation of CFD and experimental erosion results of stainless steel in various sand concentrations

CFD results of mass loss of ST-50 are compared with experimental values for different rotational velocities and sand concentrations and are presented in Fig. 11 and Fig. 12, respectively.

The CFD results are qualitatively in good agreement with experimental results for both cases.

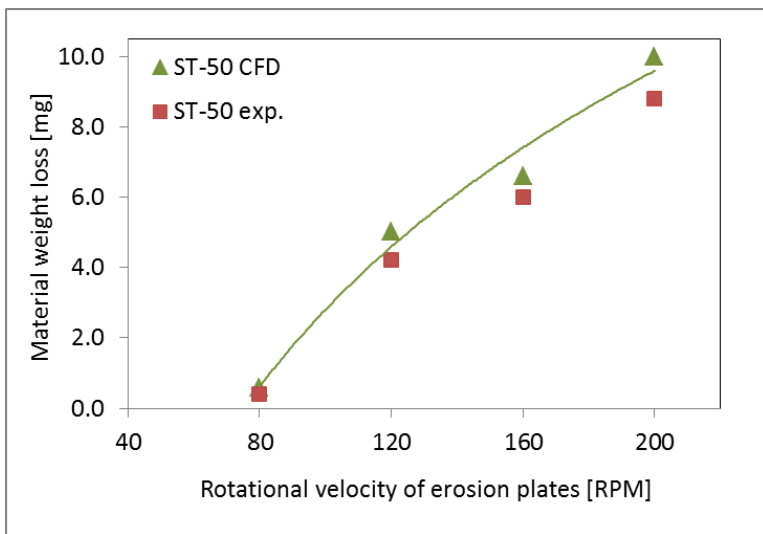

Fig. 11. Validation of CFD and experimental erosion results of ST-50 in various rotational velocities

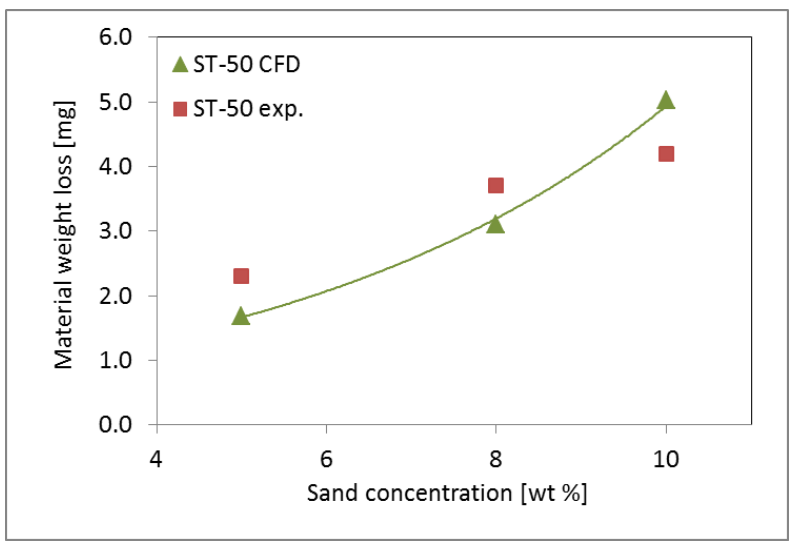

Fig. 12. Validation of CFD and experimental erosion results of ST-50 in various sand concentrations

\section{Conclusions}

A slurry tank tester has been designed and built to study the effects of erosion influencing parameters such as flow velocity, sand concentration, targetmaterial properties, target material orientation angle and etc. In the present work the effects of flow velocity and sand concentration on erosion mass loss of two different hard metals are studied.

Multiple reference frames (MRF) method is applied to simulate the slurry tank and the rotating parts with ANSYS-CFX. The general grid interface (GGI) is used since the surface mesh of stationary and rotating side of each interface are not identical. It was observed that changing the height and diameter of each rotating zones have a negligible effect on the simulation results.

It was observed that the erosion mass losses of both materials are increasing with increase in flow velocity and sand concentration. Both variations could be predicted with a logarithmic dependence 
of mass loss to rotational velocity and sand concentration.

It was also approved that the erosion mass loss of ST-50 is reasonably higher than that of stainless steel due to lower hardness of ST-50 than stainless steel and thereby lower resistance to impact effects of solid particles. A new erosion model could be developed for the accelerated erosion mass loss of materials in a slurry tank tester when effects of all influencing parameters are studied in details.

\section{Acknowledgement}

The authors would like to thank Rheinland-Pfalz Foundation for Innovation (Stiftung RheinlandPfalz für Innovation) for the financial support.

\section{References}

1. K. Sommer, R. Heinz, J. Schöfer, 1. Auflage (2010)

2. C. A. Shook, M. C. Roco, ButterworthHeinemann press, (1991)

3. R.N. Sharma, A.A. Shaikh, Chem. Eng. Sci. 58, 2123-2140 (2003)

4. P.K. Biswas, S.C. Dev, K.M. Godiwalla, C.S. Sivaramakrishnan, Mater. Des. 20, 253-265 (1999)

5. G.R. Desale, B.K. Gandhi, S.C. Jain, in: Proceedings of the 30th National Conference on Fluid Mechanics and Fluid Power, Surathkal, 528534 (2003)

6. ANSYS CFX modeling guide 12.0 (2009)

7. M. Pepple, 7th international conference on multiphase flow, ICMF 2010, Tampa, FL, May 30June 4 (2010)

8. C. G. Duan, V. Y. Karelin, Imperial college press, Vol. 2 (2002)

9. X. Chen, B.S. McLaury, S.A. Shirazi, ASME J.Energy Res. Tech. 128, 1-9 (2006)

10. X. Chen, B.S. McLaury, S.A. Shirazi, J. Comput. Fluids 33, 1251-1272 (2004)

11. G. Grant, W. Tabakoff, Cincinnati University, (June 1973)

12. I. Finnie, Wear 3, 87-103 (1960)

13. C. Huang, S. Chiovelli, P. Minev, Jingli Luo, K. Nandakumar, Powder Technology 187, 273-279

(2008)

14. M. H. Wang, C. Huang, K. Nandakumar, P. Minev, J. Luo, S. Chiovelli, Int. J. Comput. Fluid Dynamics, Vol. 23, No. 2, 155-173 (Feb. 2009)

15. W. Tabakoff, R. Kotwal, A. Hamed, Wear 52, 161-170 (1979) 